\title{
$\dot{x}$

\section{HÁBITOS DE USO DO SUTIÃ NO APL DE CONFECÇÕES E SUAS IMPLICAÇÕES NA SATISFAÇÃO}

\author{
Rosiane Pereira Alves (1); \\ Laura Bezerra Martins (2) \\ (1) Universidade Federal de Pernambuco, doutoranda. \\ e-mail: rosipereiraa211@yahoo.com.br \\ (2) Universidade Federal de Pernambuco, Doutora \\ e-mail: bmartins.laura@gmail.com
}

\begin{abstract}
RESUMO
Este artigo descreve os hábitos de uso de sutiãs por costureiras e passadeiras, que trabalham no APL de Confecções do Agreste de Pernambuco e suas implicações na satisfação durante atividade profissional. As informações foram obtidas a partir do relato das experiências anteriores de uso e os dados foram analisados qualitativamente. Foi constatado que os mesmos elementos projetuais dos sutiãs de moda, usados no contexto laboral, associados as preferências de uso e geradores de satisfação, também foram causas de desconfortos físicos.
\end{abstract}

\begin{abstract}
This article describes the habits's use of bras by seamstresses and crosswalks, that working in the APL of Textile industries and confections on Agreste in Pernambuco and its implications in the satisfaction during professional activity. The informations were obtained from reports of previous experiences of use and the data has qualitatively analyzed. It was found that the same designs elements of fashion bras, used in the employment context, associated the usage preferences and satisfaction generators were also causes of physical discomforts.
\end{abstract}

\section{INTRODUÇÃO}

Esta pesquisa foi realizada em Toritama, um dos municípios que integra o Arranjo Produtivo Local (APL) de Confecções do Agreste de Pernambuco, em função de sua atividade principal - a produção e o beneficiamento de roupas jeans.

A região apresenta alto índice de empregabilidade e absorve grande parte da mão de obra feminina em ocupações como costureira, passadeira, dentre outras. Estas mulheres trabalham cerca de 8 horas por dia e possivelmente com alta demanda de uso do sutiã.

Dadas as peculiaridades de uso da roupa no ambiente de trabalho, ocupado por corpos femininos que antes exerciam atividades rurais e passaram a integrar um novo espaço 
produtivo - das indústrias da cadeia Têxtil e de Confecções. Movimento iniciado na década de 1980, nesta localidade.

Trata-se de uma nova abordagem do uso do sutiã, se considerado que estudos anteriores tem investigado muito mais seu uso em contextos esportivos (ZHOU , 2011; BOWLES e STEELE, 2013), do cotidiano (RISIUS et. al. 2014) e da saúde mamária (GRAVE, 2014).

Se em outros espaços, o uso do sutiã tem apresentado alta importância, no ambiente formal de trabalho, pode-se dizer que há quase uma obrigatoriedade. Por exemplo, em pesquisa recente, Odebiyi et. al. (2015) encontraram elevado número de mulheres usando sutiãs apenas nas horas de trabalho $(40,5 \%)$ e outras, o dia inteiro $(43,3 \%)$.

Do ponto de vista ergonômico, o uso do sutiã pode apresentar elementos limitadores e gerar insatisfação nas trabalhadoras, com implicações negativas na execução de tarefas. Entretanto, ainda são escassas as investigações sobre a satisfação no uso do sutiã em contextos laborais.

Por isso, buscou-se saber sobre os hábitos de uso do sutiã no ambiente de trabalho e até que ponto esses hábitos interferem na satisfação das costureiras e passadeiras. Apoiada na hipótese de que ao usar sutiãs de moda no contexto laboral, as trabalhadoras estão submetidas a desconfortos físicos mais do que aos aspectos positivos do conforto.

Portanto, o principal objetivo deste artigo é descrever a experiência de uso do sutiã por costureiras e passadeiras e suas implicações na satisfação durante atividade laboral.

\section{O SUTIÃ E POSSÍVEIS IMPLICAÇÕES NA SATISFAÇÃO}

A palavra sutiã, adotada no início do século $X X$, é uma derivação da palavra francesa soutien, que significa sustenta seios (PIMENTA, 2002). Pressupõe, portanto, a ideia de funcionalidade, seja como suporte anatômico, seja pela estreita relação com elementos estéticos da sedução (FOLLI, 2010).

Anatomicamente, os seios ou mamas femininas são constituídas de glândulas, pele e tecido conjuntivo. Essas glândulas são envolvida pelos estromas de tecido conjuntivo, que em regiões especificas se condensam para formar os ligamentos de Cooper (DRAKE, VOGL e MITCHELL, 2005).

Os ligamentos de Cooper e a pele são suportes naturais da mama, que se tornam limitados em função das mudanças corporais ao longo da vida e durante a realização de atividades específicas (ZHOU, 2011). Por isso a necessidade do uso do sutiã no papel de suporte externo.

Entretanto, a interação entre muitos dos projetos de sutiãs disponíveis no mercado e, a diversidade da anatomia do corpo feminino, em grande medida, tem sido insatisfatória. Com forte recorrência de desconforto físico. Supostamente, esse tipo de desconforto pode se tornar ainda mais intenso durante a realização de atividades profissionais.

Há indícios, de que a insatisfação no uso, esteja associada a inadequação do projeto dos sutiãs às necessidades das usuárias. Apontadas por alguns estudos como resultantes do ajuste inadequado; do emprego incorreto de materiais; da priorização estética; do suporte limitado (PECHTER, 1998; ZHENG, YU, FAN, 2007; BROWN et. al. 2014). 
Isso justifica a importância de conhecer as características projetuais dos sutiãs, que desde o início do século $\mathrm{XX}$, tem sido desenhado e redesenhado. Porém, apesar das variáveis existentes em cada modelo, em sua estrutura básica há elementos ou partes, comuns à maioria dos projetos, conforme descrito na Figura 1:

Figura 1: Estrutura básica do sutiã

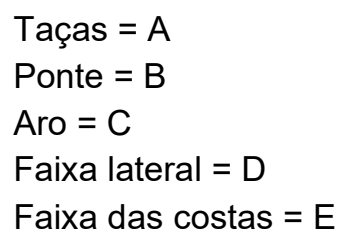

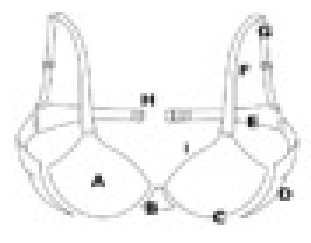

Fonte: Síntese da autora

$$
\begin{aligned}
& F=\text { Reguladores das alças; } \\
& G=\text { Alças; } \\
& H \text { = Fechos; } \\
& \text { I = Decote. }
\end{aligned}
$$

Além desses elementos projetuais, o sutiã pode ser classificados por categorias, tais como sutiãs de moda, sutiãs esportivos, sutiãs para amamentação, pós-cirúrgicos, dentre outros.

Os sutiãs de moda, usados em diferentes contextos, tem apresentado foco na estética, maior variação de modelos e coleções temporais. Por exemplo, Aiex e Martins (2013) ao analisar duas marcas brasileiras de sutiãs de moda, encontraram uma ampla oferta de modelos fashionistas com rendas, acessórios e alças estreitas. Porém, ainda é pouco conhecida a satisfação no uso dessa categoria de sutiãs em contextos laborais.

Para investigação da satisfação no uso do sutiã, os estudos sobre usabilidade se apresentam como um suporte teórico relevante, dado que a satisfação é um dos seus componentes.

O termo usabilidade surgiu no campo da interação humano-computador e foi ampliado para o estudo da interação entre usuários e produtos, a exemplo do clássico trabalho de Jordan (1998). Entretanto, segundo Falcão e Soares (2013), ainda são escassas as pesquisas sobre produtos de consumo.

Na vasta classificação de produto (de consumo), encontra-se, conforme nomeado por Fiorini (2008) o objeto de vestir, que apresenta peculiaridades de uso, diferentes da maioria dos produtos estudados pela usabilidade. Por outro lado, a usabilidade faz parte da ergonomia e esta tem contribuído, segundo Martins e Martins (2012), com a adaptação do vestuário aos usuários.

De modo que, a usabilidade pode subsidiar o estudo da interação no uso das roupas, apoiada no conceito da ABNT NBR ISO 9241-11 (2011, p.2) que define usabilidade como "a medida na qual um produto pode ser usado por usuários específicos para alcançar objetivos específicos com eficácia, eficiência e satisfação, em um contexto de uso particular."

Todavia, na presente pesquisa, optou-se por estudar apenas o componente satisfação, a partir do relato da experiência anterior de uso do sutiã no contexto de trabalho.

A ABNT NBR ISO 9241, parte 11 (2011) define satisfação como ausência de desconforto e atitudes positivas em relação ao produto. Recomenda, ainda que numa avaliação devem ser: 1) considerado o contexto de uso - usuárias, tarefas, equipamentos, ambiente físico e social e 2) determinadas as medidas de satisfação. 
Portanto, nesta pesquisa, as medidas de satisfação foram determinadas em dois níveis: 1) o desconforto físico provocado por partes específicas do sutiã; 2) a predileção por modelos e elementos projetuais e a compreensão sobre sutiã confortável.

O conforto, segundo Kolcaba e Wilson (2002), é um estado dinâmico, sujeito a mudanças rápidas, positivas ou negativas. $\mathrm{E}$ mais do que ausência de dor, pode ser transcendente com significado positivo. Pode ainda, ocupar três níveis:

1) Alívio: no qual o desagradável pode ser substituído pelo agradável;

2) Liberdade: prevenção de manifestações do desconforto;

3) Transcendência: aspectos positivos do conforto, passíveis de oferecer compensações. Neste caso pode até haver desconforto físico, se a compensação estiver em outro patamar, a exemplo do espiritual (consciência interna de si, estima, conceito, sexualidade, significado da vida) ou sócio cultural (relações interpessoais, familiares, sociais, rituais e práticas religiosas).

Esta é uma visão de conforto, extraída do contexto da enfermagem, que ajuda a entender os possíveis níveis de conforto. No entanto, Van Der Linden (2007) ressalta, que os estudos sistemáticos da relação de conforto com as características de produtos industrializados e com o ambiente de trabalho surgiram na década de 1950, pautados, desde então, em duas correntes:

1) o entendimento do conforto em oposição ao desconforto;

2) o conforto e o desconforto como duas dimensões diferentes.

No presente trabalho, ambas as dimensões foram consideradas como complementares e ocupando dois estágios diferentes, com base nos níveis apresentados por Kolcaba e Wilson (2002). Ou seja, no primeiro nível, o conforto em oposição ao desconforto, similar a busca pelo alívio. No segundo nível, as atitudes positivas, que podem ter relação com a transcendência.

\subsection{Desconforto Físico no Uso do Sutiã}

O desconforto físico pode ser compreendido como qualquer sensação desagradável, como dor, apertos, machucados, dentre outros. Estudo anteriores, apontam uma forte relação do desconforto físico com partes específicas do sutiã, é o caso das alças e dos aros. Por exemplo, a formação de sulcos nos ombros, segundo Silva (1986) pode ser provocada pelo excesso de pressão exercida por alças estreitas do sutiã, com maior recorrência em mulheres obesas, de mamas grandes, de meia idade e idosas.

Mais tarde, ao propor um modelo mecânico para avaliação da função exercida pelas alças do sutiã, Zhou (2011) identificou que diante de uma mesma força (peso da mama), as alças largas tornam-se mais eficazes do que as alças estreitas. Coltman, McGhee e Steele (2015) reforçaram que as alças largas contribuem para as mulheres sintam menor desconforto e menor pressão.

Além disso, segundo Bowles e Steele (2013), algumas mulheres, especialmente aquelas com mamas maiores, têm o hábito de apertar as alças do sutiã para sustentar as mamas. Isso transfere o peso da mama para as alças, aumenta a pressão sobre os ombros, causa dores no pescoço, na parte superior do tórax e contribui para formação de sulcos nos ombros. As autoras, ressaltam que as alças não devem ter a função de sustentação, mas de contribuir com a capacidade do sutiã ficar no lugar. 
Outro elemento projetual que tem sido relatado como causa de desconforto, são os aros. De forma semicircular, exerce a função de suporte da mama, que aliado ao preço baixo, tornouse comumente usado nos projetos desse artefato.

Porém, a mama poder sofrer deformação assimétrica, quando usando sutiãs com aros. Para evitar esse tipo de deformação, o aro deve corresponder a curva da mama em torno do tórax (LEE E HONG, 2007).

Portanto, neste nível, do alívio, não havendo relatos de desconfortos físicos provocados pelos sutiãs, pode-se dizer que há contribuição para satisfação.

\subsection{Atitudes Positivas em Relação ao Sutiã Confortável}

A atitude positiva em relação ao sutiã compõe outro nível do conforto, enquanto indicador de satisfação. Neste âmbito, a proposição de Rocha et. al. (2009) de estudar a roupa favorita como exemplo de emotividade e usabilidade, parece ser um caminho viável. Dado que:

A escolha de uma peça como a sua roupa predileta é algo a ser [...] considerado, tanto no sentido da sua carga emocional quanto em termos de usabilidade, à medida que ela já foi comparada com outras, adquirida, e testada [vestida] pelo consumidor. (ROCHA, HAMMOND e HAWKINS, 2009, p.71)

Para Rocha et. al. (2009, p.71) "o conceito de favoritismo está relacionado à preferencia por algo em detrimento de outros, e essa predileção pode estar associada a um significado especial". Todavia, ressalta-se que na presente pesquisa, o conceito de predileção foi utilizado apenas para identificar as características projetuais preferidas.

\section{METODOLOGIA E PROCEDIMENTOS}

Trata-se de uma pesquisa de campo, de caráter exploratório e natureza qualitativa. Realizada em 2014 nos espaços de trabalho das respondentes - duas confecções e uma lavanderia no município de Toritama. A obtenção dos dados se deu a partir do relato de experiências anteriores do uso do sutiã, conforme recomendação da ABNT NBR ISO 9241210 (2011), por meio dos seguintes procedimentos:

1) Apresentação e assinatura do Termo de Consentimento Livre e Esclarecido;

2) Registro das tarefas executadas via fotografia e filmagem;

3) Aplicação de entrevistas mediadas por questionário. Foram entrevistadas 5 passadeiras na Lavanderia MM, 6 costureiras na confecção M1 e 4 costureiras na confecção Z2, totalizando 15 mulheres com idade média de 30,07 anos (19-45).

Os dados foram sistematizados, ordenados por frequência e analisados qualitativamente.

\section{A EXPERIÊNCIA DE USO DO SUTIÃ POR COSTUREIRAS E PASSADEIRAS}

A maioria das entrevistadas cursaram até o ensino fundamental incompleto $(80 \%)$ com tempo de trabalho de 1 a 8 anos. Entretanto, algumas costureiras, contabilizaram até 20 anos de profissão, executados em empresas anteriores. 
Em relação a tarefa, cada costureira é especializada em um ou mais processos de montagem de partes específicas da roupa. Trata-se de um conhecimento faccionado e de tarefas executadas de forma repetitiva, com um ciclo inferior a 90 segundos. Foi observado que durante o processo de montagem, as costureiras mantiveram posição sentada, com movimentação dos membros superiores e inferiores, por vezes rotação do tronco e do pescoço.

As tarefas executadas pelas passadeiras consistiam em passar e dobrar calças jeans, com um ciclo de aproximadamente 1 minuto e 40 segundos. Adotaram a posição em pé, alternância posturais, movimentação constante dos braços, com predomínio de manejo grosseiro.

Quanto ao perfil antropométrico, a maioria das respondentes percebem suas mamas com tamanho médio $(53,3 \%)$ e Pequena $(20 \%$,$) . As demais com mamas Grandes (13,3 \%$,$) ou$ Muito Grande (13,3\%). Todas usam sutiãs do tamanho 40 ao 46.

\subsection{Hábitos de Uso}

A maioria das respondentes relatam usar sutiã desde o momento que acordam $(53,3 \%$,$) . As$ demais apenas para trabalhar $(33,3 \%)$ ou quando estão fora de casa $(13,3 \%)$. Pode-se inferir que o sutiã é aderido $100 \%$ nos espaços públicos, seja ele de trabalho ou não.

Após aquisição, segundo a maioria das entrevistadas $(46,7 \%)$, o sutiã é usado aproximadamente por 3 meses. Ou por um tempo ainda maior - 12 meses $(33,3 \%)$ ou 6 meses (20\%). Isso, quando o uso não representa um esforço. Na ocorrência de excesso de desconforto, há um descarte imediato e antecipado do sutiã. Este migra da condição de peça em uso para não uso, mesmo quando permanecem no armário.

Essa condição de não uso, justifica algumas respondentes (6,7\%) afirmarem possuir mais de 30 sutiãs. Este acúmulo pode ser considerado como um indicativo de insatisfação em relação ao uso do sutiã no contexto laboral. Tendo em vistas que as mulheres do grupo investigado passam a maior parte da semana, vestidas para trabalhar.

\subsection{Preferenciais e Características Projetuais dos Sutiãs Usados no Trabalho}

As entrevistadas apresentaram predileção por sutiãs de taças com bojo espumado (80\%) e aros na base (60\%); por alças finas $(73,3 \%)$ em detrimento de alças largas $(26,7 \%)$. Também, favoritismo por sutiãs de tecido de fibras sintéticas (40\%), mais do que por tecidos de fibra de algodão $(33,3 \%)$ e de fibras mistas $(26,7 \%)$.

Quanto ao modelo do sutiã, que é determinado, principalmente pela estrutura das taças, conforme apresentado na Figura 2. Os mais usados pelas respondentes para trabalhar são, os modelos Demi (46,7\%), Triângulo (26,7\%) e Cobertura Total (13,3\%), predominantemente com alças na posição vertical $(86,7 \%)$.

Figura 2: modelos de sutiãs

\begin{tabular}{|l|l|l|l|l|}
\hline Triângulo & Demi & Balconê & Push - up & Cobertura total \\
\hline
\end{tabular}


Entre as respondentes que afirmaram usar sutiã modelo Demi para trabalhar - $57,1 \%$ possuem mamas no tamanho médio, $28,6 \%$ mamas pequenas e $14,3 \%$ Muito Grande. Ou seja, a maioria são trabalhadoras com mamas de tamanho médio e pequena.

As entrevistadas, que relataram usar sutiãs modelo triângulo para trabalhar, $50 \%$ possuem mamas grandes, 25\% mamas muito grandes e 25\% mamas médias. Ou seja, apenas mulheres com mamas grandes e médias.

Entre aquelas que afirmaram usar sutiã modelo Cobertura total, todas (100\%) possuem mamas de tamanho médio.

Todavia, quais são as implicações dessas preferência e hábitos de uso na percepção do conforto por costureiras e passadeiras durante execução de atividades laborais? Qual o compreensão de conforto por esse grupo de trabalhadoras?

\subsection{Implicações na Satisfação}

A compreensão de conforto pelas costureiras e passadeiras, apresentou similaridades com a literatura. Por exemplo, para a maioria das entrevistadas, o conforto é um estado positivo de Bem estar (53,3\%), sinônimo de ficar a vontade e de leveza (13,3\%). As demais compreendem conforto como ausência de incômodos (20\%). (Tabela 1)

Tabela 1: Distribuição de frequência quanto ao entendimento de conforto, segundo as respondentes.

\begin{tabular}{l|l|l}
\hline CONFORTO & FREQ & $\%$ \\
\hline Ficar a vontade / Leveza & 2 & 13,3 \\
Bem estar & $\mathbf{8}$ & $\mathbf{5 3 , 3}$ \\
Não incomodar & 3 & 20,0 \\
\hline Não Respondeu & 2 & 13,3 \\
Total & 15 & 100,0 \\
\hline
\end{tabular}

O conforto, enquanto ausência de incômodos, é a expressão da percepção de conforto em oposição ao desconforto. Compõe, portanto o nível da busca pelo alívio, que pode se fixar na neutralidade.

Conforme proposto, um nível mais elevado do conforto, pode estar associado ao efeito positivo. Tendo em vista que a maioria das entrevistadas associaram conforto ao efeito de "bem estar".

Estes resultados, confirmam e reforçam a proposição de dois níveis de conforto para atingir a satisfação: Nível 1: ausência de desconforto, a busca pelo alívio e; Nível 2: presença de aspectos positivos, que podem estar relacionado a transcendência.

\subsection{Nível 1: Conforto/Desconforto Provocado por Partes Específicas do Sutiã}

Foram identificadas as partes do projeto do sutiã com maior e menor tendência de provocar desconforto físico durante o trabalho.

Para a maioria das respondentes, as principais partes do sutiã associadas aos desconfortos físicos foram os aros $(53,3 \%)$, as alças $(46,7 \%)$ e seus reguladores $(33,3 \%)$. Menores 
desconfortos, mas significativos, foram relacionados a ponte $(40 \%)$, as taças $(20 \%)$, as Faixas das Costas (20\%) e Laterais (13,3\%) e aos fechos (13,3\%). (Tabela 2$)$.

Tabela 2: Distribuição de frequência quanto ao desconforto provocado por partes do sutiã, segundo as respondentes.

\begin{tabular}{l|l|l|l}
\hline Partes do Sutiã & Total $(\mathrm{n})$ & FREQ. & $\%$ \\
\hline Taças & 15 & 3 & 20,0 \\
Ponte & 15 & 6 & 40,0 \\
Aro & 15 & $\mathbf{8}$ & $\mathbf{5 3 , 3}$ \\
Faixa Lateral & 15 & 2 & 13,3 \\
Faixa das Costas & 15 & 3 & 20,0 \\
Reguladores das alças & 15 & $\mathbf{5}$ & $\mathbf{3 3 , 3}$ \\
Alças & 15 & $\mathbf{7}$ & $\mathbf{4 6 , 7}$ \\
Fechos & 15 & 2 & 13,3 \\
Elástico do decote & 15 & 1 & 6,7 \\
\hline
\end{tabular}

Apesar de praticamente todas as partes do sutiã terem sido citadas como causas de incômodos, uma maior concentração de desconforto foi associado as alças e aos aros. Estes dados foram combinados com as características corporais e com elementos projetuais.

Por exemplo, no grupo investigado, foi verificado que em termos percentuais o desconforto provocado pelas alças teve maior recorrência entre mulheres com mamas Muito Grandes $(50 \%)$, Grandes $(50 \%)$ e Médias $(50 \%)$, quando comparada com aquelas de mamas pequenas $(33,3 \%)$.

Também houve, maior frequência de desconforto nas alças, entre as respondentes que costumavam usar sutiã do tipo Triângulo (75\%) em comparação com aquelas que usavam os Sutiãs Cobertura Total $(50 \%)$ e Demi (42\%). Além disso, $85 \%$ das entrevistadas preferiam usar alças finas.

Em relação ao desconforto provocado pelos aros, em termos percentuais, houve maior recorrência entre as mulheres com mamas pequenas $(66,7 \%, n=2)$ e médias $(75 \%)$, do que entre as mulheres com mamas grandes $(0 \%)$ e Muito Grandes $(0 \%)$.

A percepção de desconforto provocado pela presença do aro, também foi maior quando usando o Sutiã Demi $(71,4 \%)$ do que os sutiãs Cobertura Total $(50 \%)$ e triângulo $(25 \%)$. Este resultado, justifica-se, porque o modelo Demi, normalmente apresenta aro na base da taça. Diferente do sutiã triângulo, cuja maioria dos projetos não apresentam aros.

Pode-se inferir que as alças finas em sutiãs do tipo triângulo, usados durante o trabalho, foi causa de maiores desconfortos em mulheres com mamas de tamanho médio e grande. Enquanto que, a presença de aros em sutiãs do tipo Demi, resultou em maiores desconfortos entre as usuárias de mamas com tamanho pequeno e médio.

\subsection{Nível 2: Aspectos Positivos no Uso do Sutiã}

O sutiã é confortável, segundo $46,7 \%$ das entrevistadas, quando proporciona Ajuste Ótimo, ou seja, tamanho certo, permite a realização de movimentos e não aperta. Para $20 \%$, 
quando propicia bem estar, possui tecido agradável e segura as mamas. Para as demais (20\%), o sutiã é confortável se não machucar. (Tabela 3).

Tabela 3: Distribuição de frequência quanto a definição de Sutiã Confortável, segundo as respondentes.

\begin{tabular}{l|l|l}
\hline Sutiã Confortável & FREQ. & \% \\
\hline Sentir bem/tecido agradável/ segurar a mama & 3 & 20,0 \\
Não machuca & 3 & 20,0 \\
Tamanho Certo / Permite Movimento / Não aperta & 7 & $\mathbf{4 6 , 7}$ \\
\hline Não respondeu & 2 & 13,3 \\
Total & 15 & 100,0 \\
\hline
\end{tabular}

A oposição ao desconforto, está presente em Não machucar e parcialmente no Ótimo ajuste (não apertar). Neste caso, houve uma combinação simultânea do nível 1 - o alívio do desconforto com o nível 2 - a transcendência.

De maneira geral, os elementos positivos podem ser sintetizados em: 1) Ajuste ótimo (nível 1 e 2); 2) Bem estar geral - sentir bem, tecido agradável, segurar a mama (nível 2).

\section{DISCUSSÃO}

Em relação aos hábitos de uso, foi verificado $100 \%$ de adesão do sutiã nos espaços públicos - o dia inteiro $(53,3 \%)$, apenas no trabalho $(33,3 \%)$, fora de casa $(13,3 \%)$. Similar ao resultado encontrado por Odebiyi et. al. (2015) - sutiãs apenas nas horas de trabalho $(40,5 \%)$ e o dia inteiro $(43,3 \%)$. O que reforça a importância de se estudar o uso do sutiã nos espaços públicos, sobretudo o laboral.

As preferências de uso nestes espaços, também são indicativos de satisfação. A maioria das costureiras e passadeiras preferem usar sutiãs do modelos Demi, com bojo espumado, aro na base, alças verticais e finas.

Entretanto, foi encontrada maior ocorrência de desconforto físico provocados pelas alças e aros do que por outras partes do sutiã. As trabalhadoras que relataram desconforto nas alças, em sua maioria, possuíam mamas grandes e médias e usavam o sutiã Triângulo (75\%) para trabalhar. Ainda apresentaram maior preferência por alças estreitas (85\%).

Estudos anteriores também haviam encontrado relação entre machucados nos ombros e o uso de alças estreitas, com maior intensidade em mulheres de mamas grandes (SILVA, 1986). Zhou (2011) e Bowles e Steele (2013), haviam identificados, em pesquisas diferentes, que alças largas, contribuem mais para a sensação de conforto físico do que as alças estreitas.

A maior ocorrência de desconforto nas alças entre usuárias do sutiã triângulo, pode estar associada a menor sustentação oferecida por este sutiã. $\mathrm{O}$ que pode levar as usuárias a apertarem as alças, aumentando a pressão nos ombros. Dado que, estudos anteriores realizados por Bowles e Steele (2013) encontraram que o hábito de apertar as alças para 
sustentar as mamas, gera desconforto físico, porque transfere o peso da mama para os ombros.

Sobre o desconforto ocasionado pelos aros, houve maior recorrência entre as respondentes com mamas pequenas e médias e entre aquelas que costumam usar o Sutiã modelo Demi. Em contrapartida, também foi relatada elevada preferência por sutiãs com aro.

A alta ocorrência do desconforto provocado pelo aro, possivelmente é resultante do formato não correspondente a forma da mama. Isso porque, segundo Lee e Hong (2007) a forma incorreta do aro pode gerar deformação assimétrica e contribuir para o desconforto físico.

Por outro lado, o sutiã confortável, de acordo com as respondentes é aquele que oferece: ótimo ajuste - tamanho correto, permite a realização de movimentos e não aperta; não incomodam; e proporcionam bem estar, possui tecido agradável, e segura as mamas.

Portanto, a partir da percepção e relatos de experiência de uso das costureiras e passadeiras foi possível identificar dois níveis de satisfação associados as características dos sutiãs:

1) o nível mais elementar, expresso pela insatisfação em relação ao desconforto físico, provocado principalmente pelas alças e pelos aros, que leva a busca pelo alívio;

2) o nível mais transcendental, ligado a sensualidade e a funcionalidade, presentes nas preferências por alças finas, aros, bojos espumados e maior uso do modelo Demi no contexto de trabalho.

Vale ressaltar, que o nível mais elementar - da busca do conforto pela ausência de desconforto é relevante no contexto de trabalho. Dada sua contribuição para a realização das atividades sem a presença de desconforto. Por outro lado, é preciso levar em consideração tanto no processo de redesign, quanto de novos projetos as preferências das usuárias.

\section{CONSIDERAÇÕES FINAIS}

A maioria das costureiras e passadeiras usam o modelo Demi para trabalhar e preferem sutiãs com alças finas, com aros e bojos espumados. Esses hábito também tem implicações negativas na satisfação, dado que os relatos de desconforto físico, também foram, provocados principalmente pelas alças e pelos aros.

Este resultado confirma parcialmente a hipótese. Ou seja, admite que as trabalhadoras ao usarem sutiãs de moda estão de fato submetidas a desconfortos físicos, dados que praticamente todas as partes dos sutiãs, usados pelas respondentes, estiveram associadas a causa de desconfortos físicos.

Por outro lado, os principais elementos associados ao desconforto físico, foram os mesmos associados as preferências - alças finas e aros. Mas não foi possível verificar se costureiras estavam submetidas mais a desconfortos físicos do que aos aspectos positivos do conforto.

Futuros estudos podem comparar os dois níveis de conforto - do alívio e da transcendência e identificar qual deles tem maiores implicações na satisfação das usuárias de sutiãs em contextos laborais. Apesar de que, a migração do sutiã da condição de uso para condição de não uso, diante do desconforto excessivo, pode ser um forte indicador de insatisfação que pode levar a seguinte conclusão: há um equilíbrio entre os níveis do conforto - alívio e 
transcendência - para satisfação do uso do sutiã no contexto laboral. Pesquisas posteriores podem, inclusive, verificar qual é o nível suportável de desconforto, diante das preferências projetuais.

\section{REFERÊNCIAS}

ABNT NBR ISO 9241-11:2011. Requisitos ergonômicos para o trabalho com dispositivos de interação visual. Parte 11: Orientações sobre usabilidade. 2011.

ABNT NBR ISO 9241-210:2011. Ergonomia da interação humano-sistema. Parte 210: Projeto centrado no ser humano para sistemas interativos. 2011.

AIEX, Viviane Mantovani; MARTINS, Suzana Barreto. Análise dos parâmetros que influenciam na compra de sutiãs tamanhos superiores a 46. In: Projética, Londrina, v.4, n.1, Jan./Jun. 2013. p. 137-160,. Projética. Disponível em: <http://www.uel.br/revistas/uel/index.php/projetica>.

BOWLES, Kelly-Ann; STEELE, Julie R. Effects of straps cushions and strap orietantion on comfort and sports bra performance. In: Medicine \& Science in sports \& exercise. 2013. p.11131119.

BROWN, Nicola; WHITE, Jennifer, BRASHER, Amanda; SCURR, Joanna. An investigation into breast support and sports bra use in female runners of the 2012 London Marathon. In: Journal of Sports Sciences, 2014. p. 1-9.

COLTMAN, Celeste E; MCGHEE, Deirdre E.; STEELE, Julie R. Bra strap orientativos and designs to minimize bra strap discomfort and pressure during sport and exercise in women with large breasts. In: Sports Medicine. 1:21. 2015. p. 01-08

DRAKE, Richard L.; VOGL, Wayne; e MITCHELL, Adam W. M. Gray's, anatomia clínica para estudantes. Trad. Vilma Ribeiro de Souza. Rio de Janeiro: Elsevier, 2005.

FALCÃO, Christianne Soares; SOARES, Marcelo Marcio. Usabilidade de Produtos de Consumo: uma análise dos conceitos, métodos e aplicações. Revista Estudos em Design (online). V. 21. n. 2. Rio de Janeiro. 2013. p. 01-26.

FIORINI, Verônica. Design de moda: abordagens conceituais e metodológicas. In: PIRES, Dorotéia Baduy (org.). Design de moda: olhares diversos. Baureri, SP: Estação das Letras e Cores Editora, 2008. p. 93-114.

FOLLI, Anna. Lingerie: the evolution of seduction. (Editado por FABIANIS, Valeria Manferto. Traduzido por Catherine Howard). Vercelli, Italy: White Star, 2010.

GRAVE, Fátima. O design e o vestuário: sutiã ergonômico para mulheres mastectomizadas com sequelas linfáticas. (Tese de doutorado). Engenharia Têxtil. Universidade do Minho. Guimarães-Portugal, 2014.

JORDAN, Patrick. W. An Introduction to Usability. London, Taylor \& Francis, 1998.

KOLCABA, Katharine; WILSON, Linda. Comfort Care: a framework for Perianesthesia Nursing. In: Journal of PeriAnesthesia Nursing, Vol 17. N. 2. April, 2002. p. 102-114. 
LEE, Hyun-Young; HONG, Kyunghi. Optimal brassiere wire based on the 3D anthropometric measurements of under breast curve. In: Applied Ergonomics. v.38 2007. p. 377-384.

Loungerie. Disponível em: < http://www.loungerie.com.br/sutia-perfeito.html>. Acesso em 20 jun 2016.

MARTINS, Suzana. B.; MARTINS, Laura. B. Ergonomics, design universal and fashion. Work: A Journal of Prevention, Assessment and Rehabilitation, Volume 41, Supple-ment 1/ 2012, IOS Press. p. $4733-4738$.

ODEBIYI, Daniel O.; AWETO, Happiness A.; GBADEBO, Olumide A.; OLUWOLE, Ayodeji A.; AIYEGBUSI, Ayoola I. Association between suitability of bra fit and pectoral girdle. In: International Journal of Therapy and Rehabilitation. Vol. 22 N. 9. September, 2015. p. 428-433.

PECHTER, Edward A. A new method for determining bra size and predicting postaugmentation breast size. In: Journal Costemic Ideas na Innovations. 1998. p. 1259-1265.

PIMENTA, Reinaldo. A casa da mãe Joana. Rio de Janeiro: Elsevier, 2002.

RISIUS, Debbie; THELWELL, Richard; WAGSTAFF, Christopher R. D.; SCURR, Joanna. The influence of ageing on bra preferences and self-perception of breasts among mature women. In: Journal Eur. Ageing. N. 11. 2014. p. 233-240.

ROCHA, Maria Alice Vasconcelos; HAMMOND, Lynne; HAWKINS, David. Os Indicadores do Consumo de Moda-Vestuário: compreendendo preferencias por meio da roupa predileta. Oikos (Viçosa, Mg), v.20, 2009. p.57-76

SILVA, Deonísio da. De onde vêm as palavras: origem e curiosidades da língua portuguesa. 17 ed. Rio de Janeiro: Lexikom, 2014.

VAN DER LINDEN, J. Ergonomia e Design: prazer, conforto e risco no uso dos produtos. Porto Alegre, UniRitter Ed, 2007.

ZHENG Rong; YU, Winnie; FAN, Jintu. Development of a new chinese bra sizing system based on breastanthropometric measurements. In: International Journal of Industrial Ergonomics. Volume 37. 2007. p. 697-705.

ZHOU, Jie. New methods of evaluating breast motion in braless and sports conditions. (Tese de Doutorado) The Hong Kong Polytechnic University. 2011. 